\title{
Recent advances on mitigating wax problem using polymeric wax crystal modifier
}

\author{
Bing Wei
}

Received: 8 July 2014 / Accepted: 17 November 2014/Published online: 4 December 2014

(c) The Author(s) 2014. This article is published with open access at Springerlink.com

\begin{abstract}
The petroleum industry has addressed wax problems since its inception. Every year, considerable resources are expended on wax removal, which accordingly cause significant economic loss. As one of the materials in chemical treatments, polymeric compounds referred to as "wax-crystal modifier", is being widely used to improve flow properties and/or combat wax deposition for waxy crude oils. This article reviews the recent achievements with regard to the flow improvement and wax inhibition of waxy oils using traditional polymeric wax crystal modifiers, such as ethylene-vinyl acetate (EVA), poly(ethylene-butene) (PEB), and polyethylenepoly(ethylene-propylene) (PE-PEP), as well as the development of novel polymers for potential use in the near future. The goal of this review is to assist people understand the advances in this topic.
\end{abstract}

Keywords Waxy oil - Polymeric wax crystal modifier . Wax inhibition · Flow improvement - Recent advances

\section{Introduction}

It is well known that crude oil is a complex mixture containing paraffins, aromatic hydrocarbons, resins, and asphaltenes. Among them, paraffins are considered as a major challenge, especially for the upstream petroleum industry. The solubility of high-molecular paraffins is strongly related to the temperature. With the decreasing

\section{B. Wei $(\bowtie)$}

Department of Chemical Engineering,

University of New Brunswick, Headhall,

15 Dineen Dr., Fredericton, NB E3B 5A3, Canada

e-mail: p5wfr@unb.ca temperature, these paraffins tend to precipitate and form stable wax crystals. The wax crystals will deposit on the pipe wall and/or transport with fluids, which would reduce the flowability of crude oils and plug pipelines or seize equipments, leading to costly downtime and expensive remediation techniques (Bacon et al. 2010; Bello et al. 2006).

Wax deposition occurs when the oil temperature is lower than the wax appearance temperature (WAT) and a temperature gradient exists between the crude oil and colder deposition surface (Jennings and Breitigam 2010; Venkatesan et al. 2012). This process usually includes three stages: (1) paraffin begins to crystallize forming a crystal nucleus when the temperature is below WAT; (2) paraffin crystals become larger with more paraffin molecules precipitating and growing upon the nucleus; (3) the grown crystals deposit on the surface of pipelines and production facilities (Zhang et al. 2014). Wax deposit gives rise to problems during crude production, storage, transportation, handling, and processing, which could cost up to billions of dollars a year worldwide (Towler et al. 2007).

\section{Wax deposition: removal and prevention}

Numerous methods have been established to handle wax deposition problem, which can be generally divided into two categories: removal and prevention. The removal techniques applied in oilfields include mechanical (pigging), thermal (hot water or oil), and chemical (solvents) methods; while, for the prevention or inhibition of wax deposition, dispersants and crystal modifiers are usually employed, and these chemicals are known as "wax inhibitor" (Dobbs 1999). In reality, a combination of two or more methods is usually used. Currently, the mechanical 
Fig. 1 Schematic representation of wax crystal modifier co-crystallization with wax crystals (source: Al-Yaari 2011)

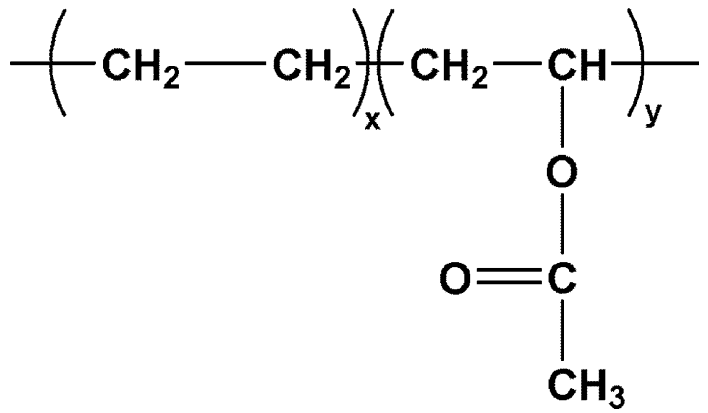

Fig. 2 Chemical structure of ethylene-vinyl acetate copolymer

method, pigging, is the most common wax removal technique, especially in the offshore subsea systems. However, this operation is suggested to be performed as seldom as possible due to the high cost. The actual cost of operating pigging may be not very significant, but the potential cost associated with using pigging such as deferred production is substantial. Therefore, in the interest of having more

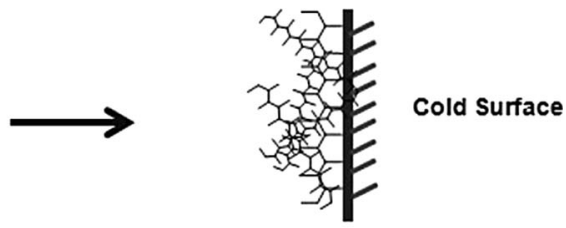

Depositing to Cold Surface
Wax Crystal Modifier

Interfering with Agglomeration

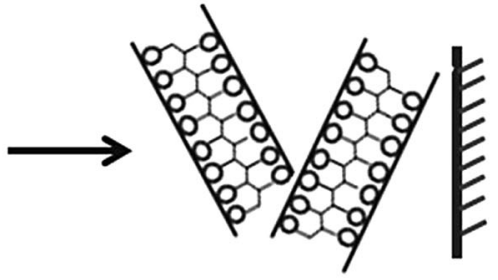

Interfering with Deposition

economic return, pigging frequency must be markedly reduced. This is the main reason that wax crystal modifiers are being so extensively used. Although this kind of chemicals cannot provide complete wax inhibition, they can effectively reduce the wax deposition rate and in turn delay the build-up of wax deposits (Pedersen and Rønningsen 2003).

Wax crystal modifiers are materials that have similar chemical structure to the wax that is precipitating. The typical wax crystal modifiers are polymeric compounds constituted by one or more hydrocarbon chain(s) (wax-like) and polar portion. This type of compounds can co-precipitate or co-crystallize with wax by occupying the position of wax molecules on the crystal lattice through the hydrocarbon chains; meanwhile, it also places a steric hindrance on the crystal which can interfere the growth and aggregation of wax crystals, and frequently reduce the pour point of crude oils (Machado et al. 2001; Paso and Fogler 2004). This process is clearly illustrated in Fig. 1 (Al-Yaari 2011).

Fig. 3 SEM images of wax crystals without EVA (a) and with 100 ppm EVA (b) (source: Jafari Ansaroudi et al. 2013)
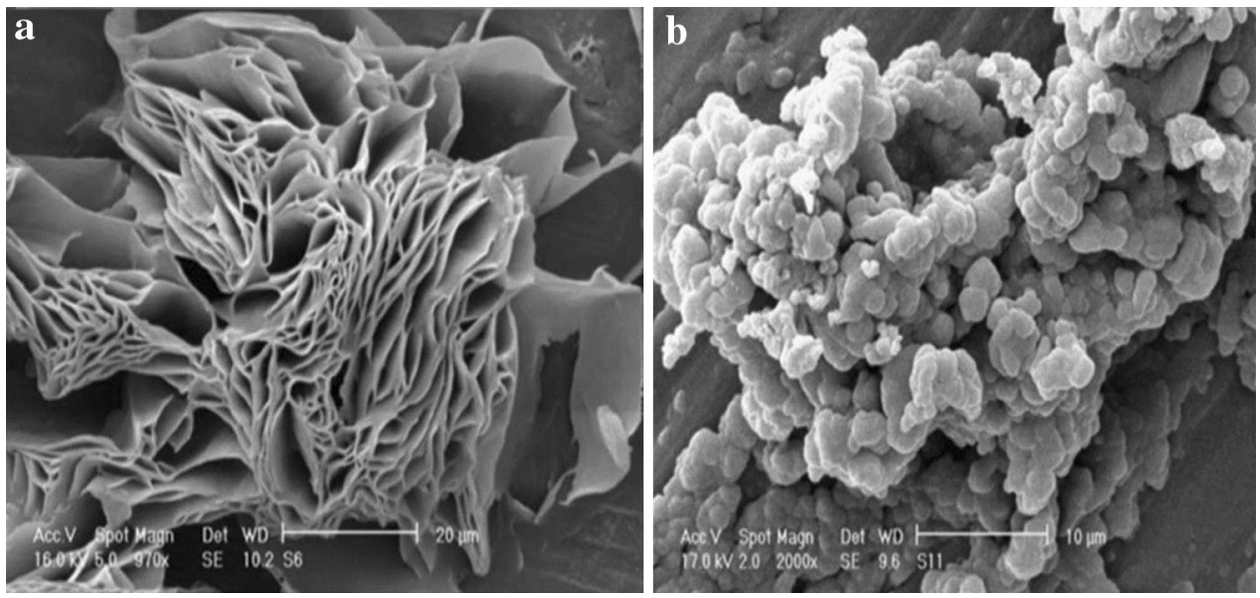
In this paper, recent works related to flowability improvement and/or wax inhibition of waxy oils using conventional and novel polymeric wax crystal modifiers are reviewed, aiming to provide an up to date synopsis of this issue.

\section{Ethylene-vinyl acetate (EVA)}

Compared to other polymers, ethylene-vinyl acetate copolymers (EVA) are the most extensively used wax crystal modifiers. This kind of copolymers has a linear chain composed of polyethylene portion with varying length depending on the quantity of co-polymerized monomer (vinyl acetate). The chemical structure of EVA is shown in Fig. 2. It has been recognized that the EVA copolymers exhibit varying degree of capacity in controlling the size of formed wax crystals (Vieira et al. 2012). When EVA is successfully used, the produced crystals are considerably smaller and more numerous than those crystallized from untreated systems (Petinelli 1979).

The influence of EVA copolymers containing different content of vinyl acetate on the viscosity and pour point of a Brazilian crude oil was investigated by Machado et al. (2001). The results revealed that EVA 30 (vinyl acetate content: 30 $\mathrm{wt} \%$ ) is the most efficient copolymer for pour point depression compared to other evaluated copolymers which have 20 , 40 , and $80 \mathrm{wt} \%$ of vinyl acetate. A similar tendency was also observed by Petinelli (1979) and Yang et al. (2009). In addition to the content of vinyl acetate, it seems that the molecular weight and polydispersity of EVA copolymers also affect the phase behavior and pour point depression of crude oils. Jiang et al. (2006) found that the optimum molecular mass of EVA for pour point depression is $1.2 \times 10^{4} \mathrm{Da}$, but the influence of the relative molecular mass distribution is negligible. This conclusion might be appropriate for asphaltene-free oils; however, for the asphaltene oils, the situations would become more complicated (Taraneh et al. 2008).

The effect of asphaltene on the EVA performance with respect to flow properties' enhancement of wax synthetic systems (a solvent mixture, paraffin, and petroleum asphalt residue) was given by Brar and Kumar (2002). This study proved that the presence of petroleum asphalt residue would reduce the efficiency of the EVA copolymers. Consistent with previous reports, the vinyl acetate content of $32 \mathrm{wt} \%$ is the optimum composition for most of the

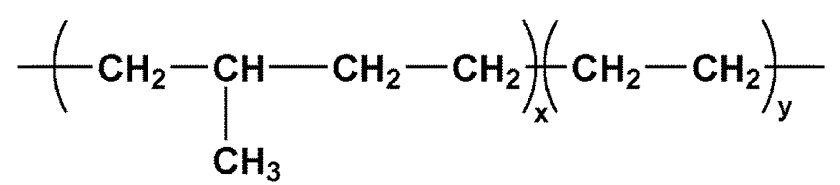

Fig. 4 Chemical structure of polyethylene-poly(ethylene-propylene)

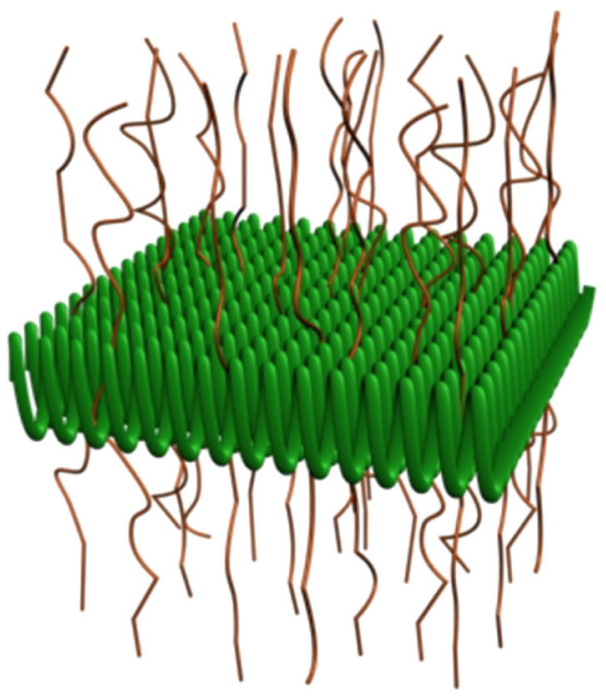

Fig. 5 Self-assembly of polyethylene-poly(ethylene-propylene)

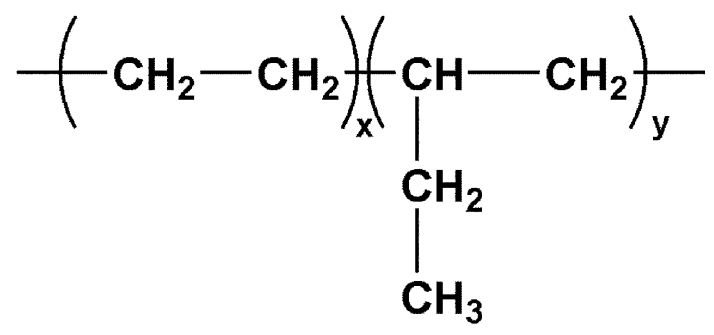

Fig. 6 Chemical structure of poly(ethylene-butene)

cases. Moreover, this copolymer (EVA 32) was found to be more efficient for the systems composed of high carbon number paraffins. This pioneer work was followed by Ashbaugh et al. (2005) who suggested that at the same dosage of EVA, the efficiency of flowability improvement decreases with the decreasing wax carbon number, which is somehow consistent with Brar and Kumar's findings. They also stated that the EVA copolymers could remarkably reduce the size of wax crystals, as well as change the particle from plate-like to a more compact and spherical morphology. Very similar phenomenon was obtained by Jafari Ansaroudi et al. (2013) who used scanning electron microscopy (SEM) to observe the morphology of wax crystal as shown in Fig. 3.

Marie et al. (2005) described the crystallization process of paraffins from solution in the presence of EVA copolymers (28 wt \% vinyl acetate; $M_{\mathrm{W}}=10,800 \mathrm{~g} / \mathrm{mol}$ ). The experimental data indicated that the mechanisms of crystal formation and growth are different depending on the type of solvent and distribution of paraffin molecule length. EVA can function either as a nucleating agent or a growth inhibitor. Due to close energies of interaction between different paraffin-like components, minor changes of experimental conditions may lead to dramatic effects.

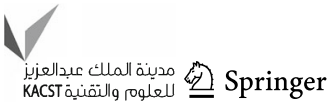


In terms of solvents, it is well known that wax inhibitors are usually formulated with active compounds (crystal modifiers) dissolved in organic (aromatic) solvents for oilfield use (Jennings and Newberry 2008). In other words, the performance of the wax crystal modifiers may be further improved if a synergistic effect exists between EVA and solvent(s). Lashkarbolooki et al. (2011) evaluated several solvents and eventually proposed an optimum formulation for wax inhibition, i.e., $50 \mathrm{wt} \% \mathrm{EVA}+25 \mathrm{wt} \%$ Acetone $+25 \mathrm{wt} \%$ p-xylene, which could give up to $53 \%$ reduction in the amount of wax deposition. Therefore, the formulation of wax inhibitors must be optimized before application due to the significant influence of solvent(s) (Qian et al. 2002).

Theoretical studies of wax inhibition using EVA copolymers were performed by Lindeman and Allenson (2005) and Zhang et al. (2008). Lindeman and Allenson provided a new approach using theoretical modeling to correlate the molecular structure of polymer with the experimental physical properties, which can be used to predict the wax inhibition performance of EVA copolymers. While, Zhang et al. established a simple rational model to estimate the minimum dosage of EVA-type copolymers for oils with different paraffin contents. The other interesting research was conducted by $\mathrm{Wu}$ et al. (2005) who successfully used molecular dynamic simulation to explore the interaction mechanism between crystal planes of wax and EVA, as well as its derivatives with branches of propylene and butylenes, respectively. This simulation indicated that EVAP with one branch (propylene) adjacent to the VA group is a better flow improver than EVA.

\section{Polyethylene-poly(ethylene-propylene) (PE-PEP)}

Polyethylene-poly(ethylene-propylene) diblock copolymers have been demonstrated to be able to function as nucleators for wax crystal size control in middle distillate fuels (Leube et al. 2000; Monkenbusch et al. 2000). Figure 4 shows the chemical structure of PE-PEP. This type of copolymers undergoes self-assembly to yield plate structure, which in turn serves as wax crystal nucleation platform promoting nucleation of long-chain paraffins through
Fig. 7 Synthesis of poly(maleic anhydride amide co- $\alpha$-olefin)

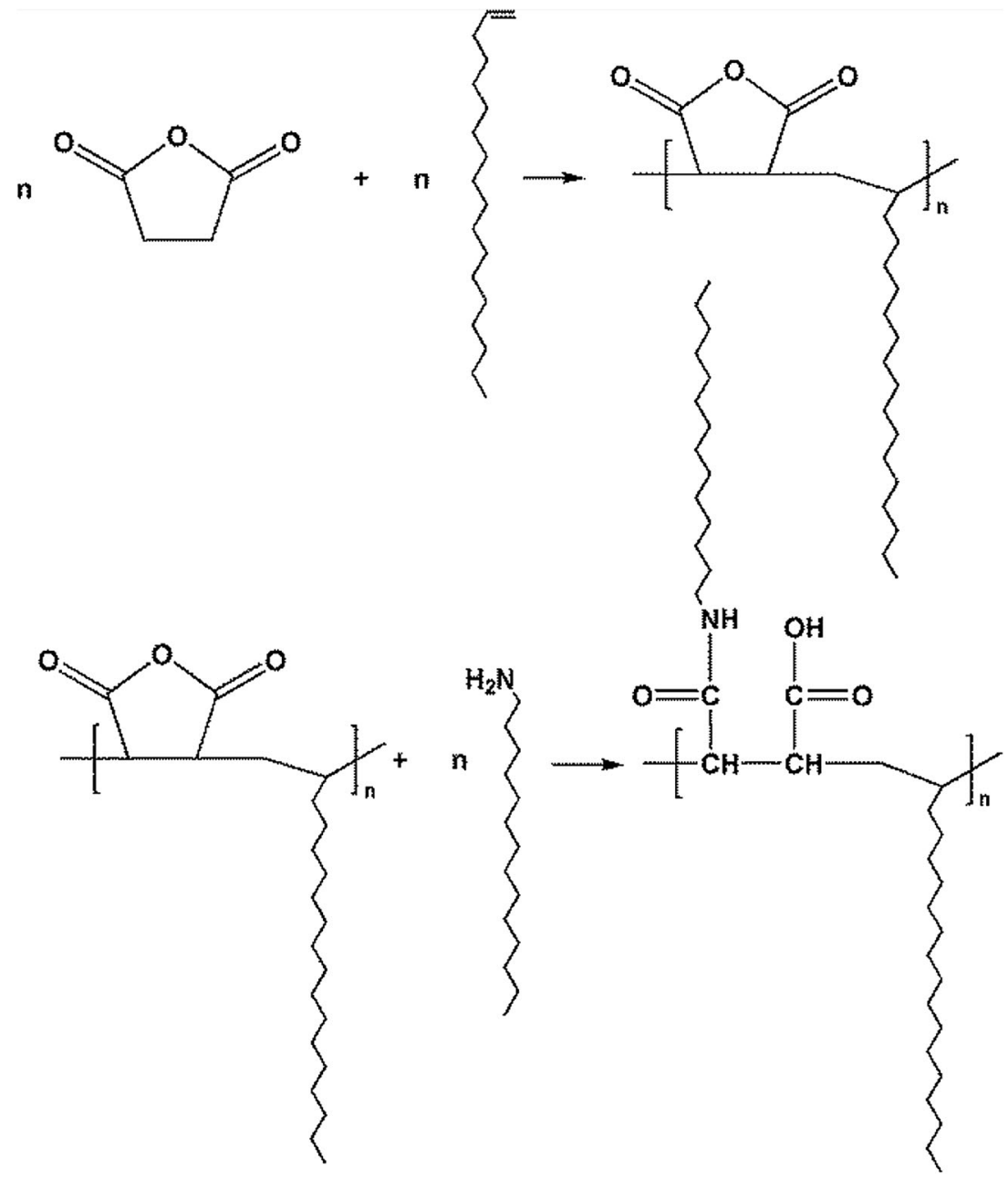


<smiles>[B]C(CCCCCCCCC(CC)CCC)CCCCCCCC(CCCC)CCCCCCCCCCCCC(CSCC(=O)O)CSCC(CC)CCCC</smiles>

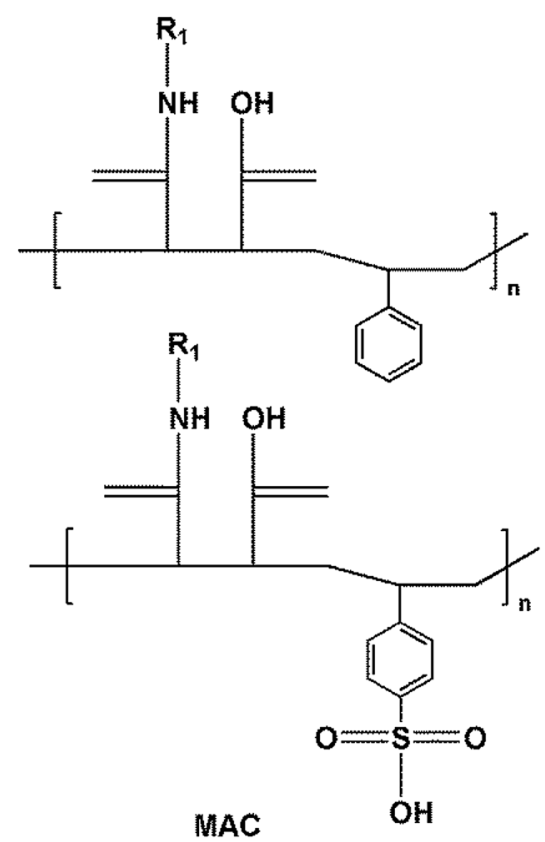

Fig. 8 PEB and MAC polymers with polar and/or aromatic modifications $(R=12,22)$

Table 1 Physical properties of waxy oil and the corresponding measure techniques

\begin{tabular}{ll}
\hline Properties & Techniques \\
\hline Wax deposition & Coldfinger, Cold disk, Cold spot test, etc. \\
Wax & Scanning electron microscopy(SEM), optical light \\
morphology & microscopy, cross-polarized microscopy (CPM) \\
Formation of & X-ray diffraction \\
wax & \\
WAT or cloud & CPM, differential scanning calorimetry (DSC), \\
point & visual observation (ASTM method), viscometry \\
Pour point & Visual observation (ASTM method) \\
Flowability & Viscometry, yield stress, flow loop test \\
\hline
\end{tabular}

providing large PE surface area. Afterwards, expansive aggregates are formed consisting of a PE core cloaked behind the amorphous PEP brush layer as illustrated in Fig. 5. This characteristic makes PE-PEP copolymers promising flow improvers for waxy crude oils (Ashbaugh et al. 2002; Schwahn et al. 2002b). However, researches addressing the application and mechanism of PE-PEP in flow improvement and/or wax inhibition are rarely reported in recent years.

\section{Poly(ethylene-butene) (PEB)}

The interesting behaviors of PE-PEP aroused researchers to evaluate other polymer architectures, in which semi-crystalline and amorphous are combined in an alternating patter as presented in Fig. 6. As one of such candidates, poly(ethylene-butene) (PEB) has attracted significant research attentions.

Schwahn et al. (2002a) studied the co-crystallization process of a $\mathrm{PEB}$ random copolymer with $\mathrm{C}_{24}$. It was observed that, contrary to PE-PEP, the random PEB cocrystallizes with wax in thin sheets constituted of a single paraffin layer surrounding by amorphous polymer hairs on both plate sides. Meanwhile, polymer is homogeneously distributed in the wax-stabilized plate indicated by the well-defined polymer brush.

Intensive investigations of the interaction between wax and PEB polymers were conducted by Guo et al. (2004b). According to their experiments, the addition of PEB polymers to long-chain wax solutions in decane leads to heterogeneous nucleation on cooling. Wax tends to crystallize into quite complex shape such as rod-like or shuttlelike structures under the interference of PEB. These structures can reduce the yield stress of waxy oils compared to the plate-like crystals formed in the absence of PEB (Guo et al. 2004c, 2006; Tinsley et al. 2007a). In addition, they provided a kind of hydroxyl-grafted PEB polymer (PEB-OH), which seems more efficient in reducing the yield stress of asphaltene-contained crude oils than PEB which can be interpreted by the dispersion effect of the polar group $(-\mathrm{OH})$ (Guo et al. 2004a).

Radulescu et al. (2006 and 2004) evaluated the performance of PEB 7.5 (7.5 ethyl branches per 100 backbone carbons) on co-crystallizing different paraffin waxes (C24 and C36) from solutions. This evaluation revealed that the efficiency of PEB 7.5 in controlling the crystallization of long wax molecule $(\mathrm{C} 36)$ is relatively greater than that of short wax molecule (C24). However, for a certain wax molecule, Guo et al. (2004c) claimed that PEB 10 which has an average 10 ethyl branches per 100 backbone carbon is more active in reducing the yield stress than PEB 7.5. 


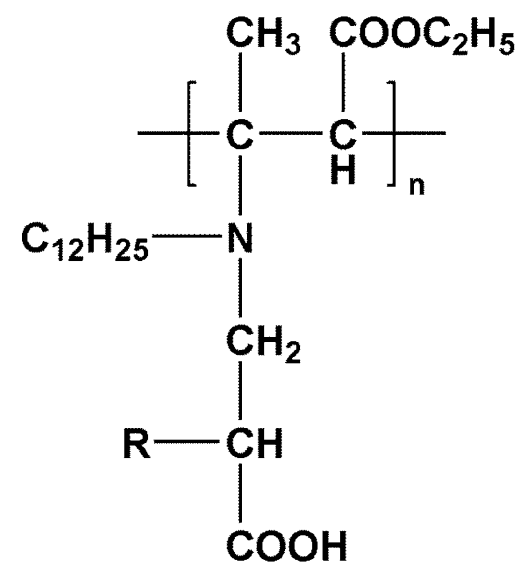

Fig. 9 Chemical structure of the hydrophobically modified polybetaines

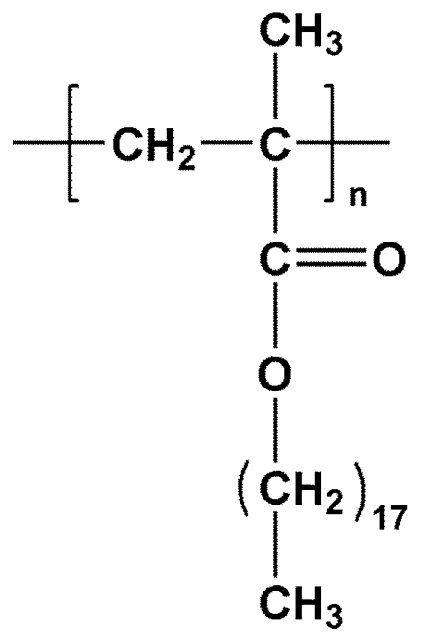

Fig. 10 Chemical structure of ODMA

These experimental results suggest that the overall performance of wax crystal modifiers is dependant not only on the wax structure but also on the structure of themselves (Ashbaugh et al. 2005).

In a more recent work, Radulescu et al. (2011) investigated the self-assembling behavior of multiblock copolymer consisting of PEB- $n$ random polymers, in which the association mechanism was proposed aided by the investigation of these multiblock polymers in the presence of waxes.

\section{Poly(maleic anhydride amide co- $\alpha$-olefin) (MAC)}

Poly(maleic anhydride amide co- $\alpha$-olefin) (MAC) is another class of polymeric additives for waxy crude oils, which has been commercially used to retard wax deposition. Figure 7 shows the synthesis route of poly(maleic anhydride amide co- $\alpha$-olefin) (Xu et al. 2009; Li et al. 2012).
Del Carmen García (2000) investigated the effect of heavy linear alkanes $(\mathrm{C} 24+)$ concentration on the effectiveness of MAC polymers on wax inhibition. It was demonstrated that $\mathrm{C} 24+$ waxes are deleterious for the efficiency of MAC functioning as a wax crystal modifier. Moreover, the presence of flocculated asphaltenes in crude oil would generate crystallization sites, which increase the cloud point of the crude oil and interfere with the crystal inhibition of MAC.

Tinsley et al. (2007a, b) compared the performance of three effective polymeric wax crystal modifiers, EVA, PEB, and MAC, using a laboratory deposition cell. In terms of the efficiency in yield stress reduction, these polymers could be ranked as PEB, EVA followed by MAC. While, the effects of altering microcrystallinity or alkyl appendages had minor affects compared to polymer type. It was also found that MAC polymers produced the largest alteration in crystal structure. A further investigation performed by Tinsley et al. (2009) was to examine the effects of a set of polymer additives (PEB and MAC) having controlled crystalline and polar content (Fig. 8) on asphaltene waxy oil. Results indicated that the presence of polar functionalities designed to target interaction with asphaltene was not beneficial. MAC polymers seem behave better than PEB polymers. Furthermore, the efficiency of yield stress reduction increases with the length of wax molecule, which can be attributed to the ability of polymers to co-precipitate with wax. Asphaltene has different effects on polymer performance depending on the property being measured. Table 1 lists physical properties of waxy oil and the corresponding measure techniques that have been applied.

$\mathrm{Xu}$ et al. (2009) presented a work entitled how combtype poly(maleic acid alkylamide-co- $\alpha$-olefin) assembles in waxy oils and improves flow ability, in which the performance of a series of MACs with different side-chain lengths was evaluated. It was proved that MAC polymers either self-assemble to nucleate the crystallization of paraffins or co-crystallize with them to inhibit wax crystal growth. The polarized-light microscopy observations demonstrated that the size of wax crystals was reduced significantly by MAC polymers. MAC 18-18, which has the longest side chains, is more efficient in improving the flowability of crude oils relative to MAC 12-18 and MAC 12-12.

$\mathrm{Li}$ et al. (2011) studied the crystallization of long-chain paraffins from solutions by X-ray diffraction. Upon addition of PEB or MAC, the low-angle scatterings from the layer structures were reduced and even disappeared. This fact implies that these polymers anchor into crystals by cocrystallization with paraffins and the non-crystallizable portion of the polymers provided a steric barrier against platelet stacking. For waxy crude oils containing 
Fig. 11 Chemical structures and contents of the commercial phosphoric ester mixture<smiles>CCCCCCCCCCCCOP(=O)(O)O</smiles>

$1.4 w t \%$

$3.3 \mathrm{wt} \%$

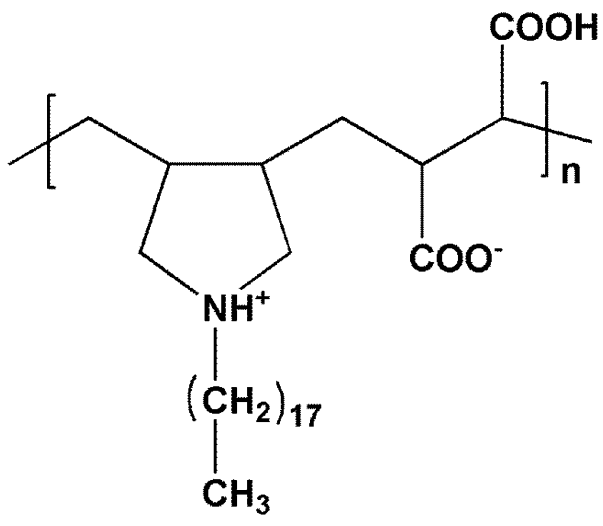

asphaltene, MAC was proved to be more effective than PEB in improving the flowability. The interaction between the carboxyl and amide groups of MAC with the polar aromatic asphaltenes appears to stabilize crudes through the steric effect of the long alkyl groups (Guo et al. 2005; Li et al. 2012).

\section{Newly developed polymers}

EVA, PE-PEP, PEB, and MAC could be classified as the conventional wax crystal modifiers. Based on the above extensive investigations, some novel polymeric compounds have been successfully synthesized in the past few years.

Didukh et al. (2004) synthesized a new type of hydrophobically modified polybetaines (Fig. 9), which could be employed as flow improver for waxy oil. When this polymer dissolved in $n$-heptanes, the pour point of crude oil was decreased by $18^{\circ} \mathrm{C}$. While, for yield stress reduction, the best formulation was obtained when it was dissolved in $o$-xylene, approximately seven times yield stress could be reduced in comparison with crude oil itself. The performance of this polymer for a Malaysian waxy crude was systematically evaluated by Halim et al. (2011). As a conclusion, 1,000 ppm is the optimum dosage.

A synthetic polymer, polyoctadecylmethacrylate (ODMA), was used for wax inhibition by Wang et al. (2003). The chemical structure of ODMA is presented in Fig. 10. In this study, the ability of ODMA compared to some commercial wax inhibitors with respect to WAT depression and wax deposition was evaluated. In the case of ODMA, the wax deposition was decreased by more than $50 \%$. However, it has no discernible effect on heavy paraffin $\left(\mathrm{C}_{35}\right.$ and above) deposition, which is similar for most of the commercial chemicals.

Gentili et al. (2005) synthesized three polymeric additives through the reaction of a commercial phosphoric ester mixture and sodium aluminate. The structure and content alt-(maleic acid)]

of the commercial phosphoric ester mixture are shown in Fig. 11. The molecular weight of the product was controlled by the content of the reagent. It was demonstrated that the waxy oil was maintained at a low viscosity after treated with them. Regarding crystallization process, it seems that this type of polymers does not alter the manner of paraffin crystallization, but avoid the agglomeration of the wax crystals.

A hydrophobically modified polymer, namely $\operatorname{poly}(N, N$ diallyl- $N$-octadecylamine-alt-(maleic acid)) (Fig. 12), was synthesized by Kudaibergenov et al. (2005). This polymer was exhibited to act as an efficient flow improver and wax inhibitor for a waxy crude oil (Askshabulak Oilfield). The efficiency of the polymer results from the presence of long hydrophobic chains and strongly interacting zwitterionic moieties.

A group of maleic anhydride-based copolymers was developed by Soni et al. (2005, 2008, 2010). Some of examples are given in Fig. 13. They found that all the synthetic polymers satisfied most of the requirements for flowability improvement and wax inhibition of waxy oils. In the case of polymer $b$ and $c$, the percentage of wax 


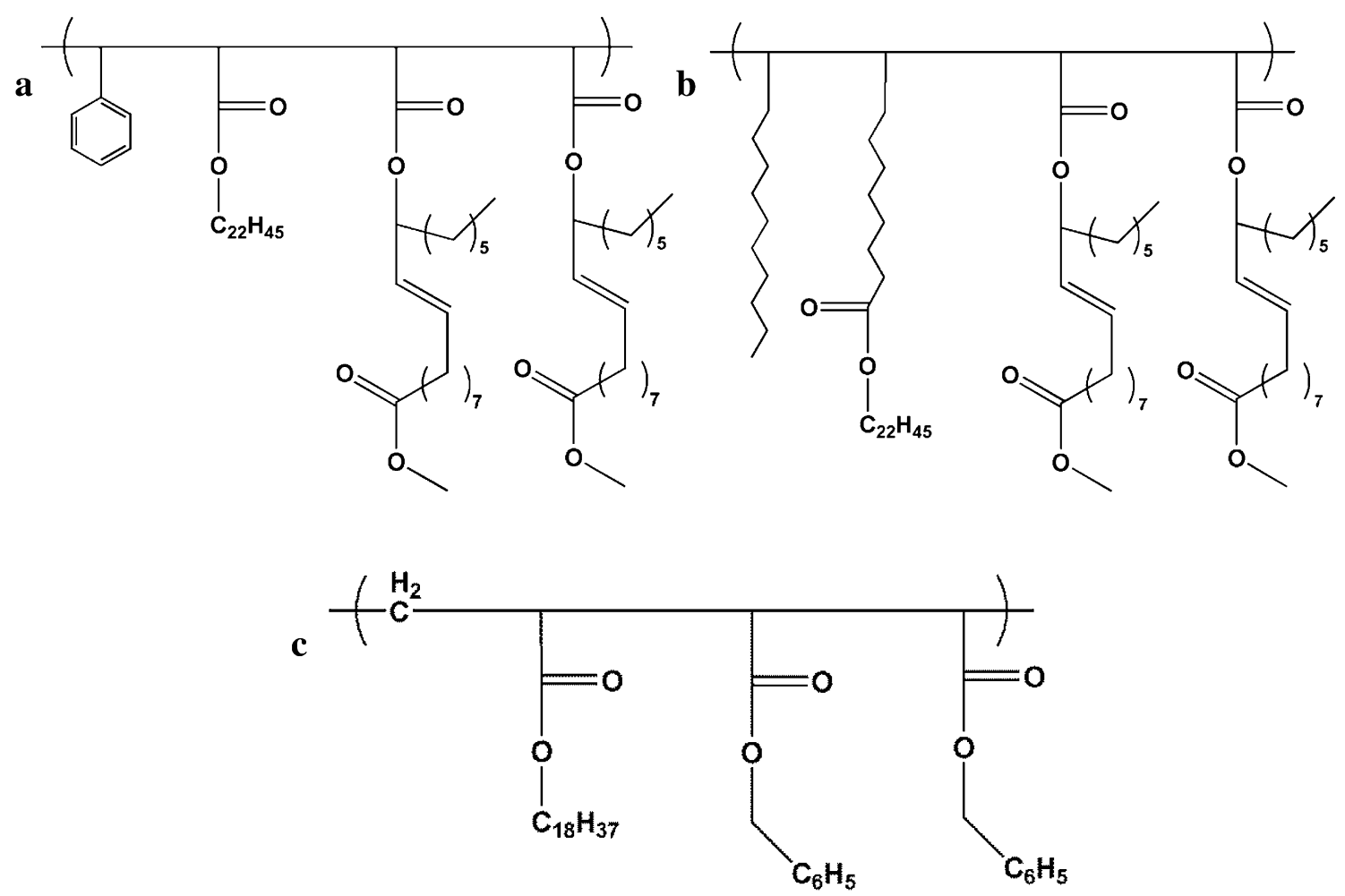

Fig. 13 Chemical structures of maleic anhydride-based copolymers<smiles>[R]OC(=O)C(C(CCC(C)(C)C)c1ccccc1)C(C(=O)O)C(C)(C)C</smiles>

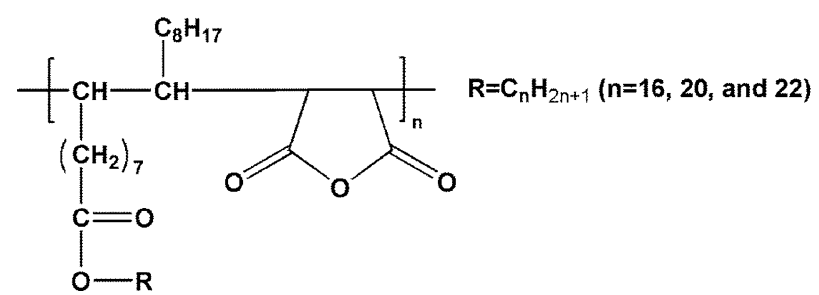

Fig. 14 Chemical structures of styrene maleic anhydride copolymer (upper) and poly alkyl oleate-co-succinic anhydride (bottom)

inhibition was up to 63 and $67 \%$, respectively. These excellent performances could be attributed to the presence of hydrocarbon chains, double bonds, and/or aromatic parts. Similarly, structural polymers were synthesized by
Al-Sabagh et al. $(2009,2013)$ as shown in Fig. 14. The experimental data indicated that all the polymers imposed a positive effect on the viscosity corresponding to improved flowability. Nevertheless, the maximum efficiency was obtained from the samples which have the longest branch chains (C18, left; C22, right), which is in agreement with the report elsewhere ( $\mathrm{Xu}$ et al. 2009).

El-Ghazawy and Farag (2010) investigated the performance of docosanyl acrylate-co-(octadecyl or hexadecyl acrylate)-co-maleic anhydride terpolymers as flow improvers. In this study, the influence of composition and concentration of terpolymers on yield stress reduction of two crudes were examined and the optimum conditions were proposed.

A series of novel polymeric crystal modifiers, polyaminoamide (PAA), were prepared by aminolysis and polycondensating using vegetable oil as shown in Fig. 15 (Chen et al. 2011). Through evaluations, it was proved that all the PAA polymers are effective in inhibiting wax deposition, in which PPC-2 derived from canola oil and polyethylene
Fig. 15 Synthesis route of polyaminoamide (PAA)<smiles>[R]C(=O)OC[C@@H](OC([R])=O)[C@@H](CN)OC([R])=O</smiles> 
Fig. 16 Polarizing light micrographs of crystal in crude (left) and in PPC-2 treated crude (right) (source: Chen et al. 2011)
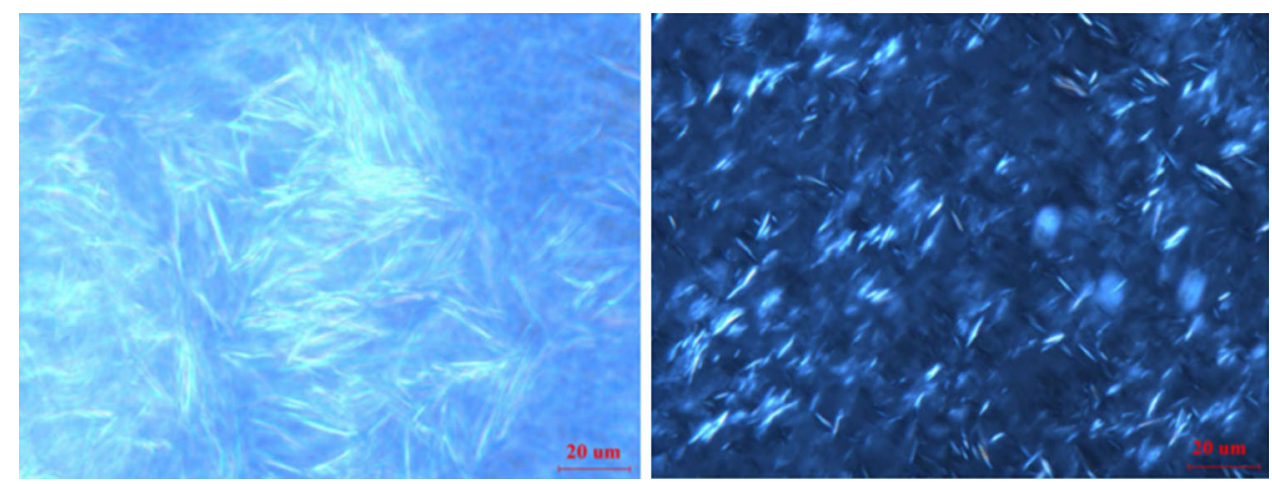

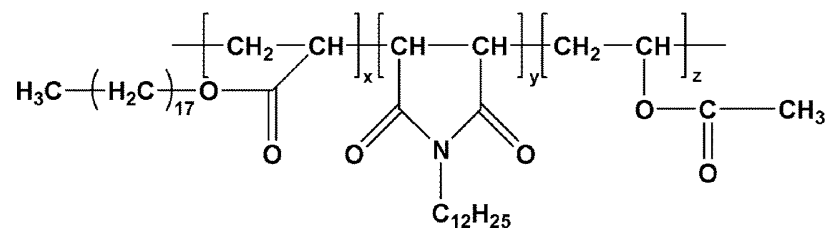

Fig. 17 Molecular formula of MAVA

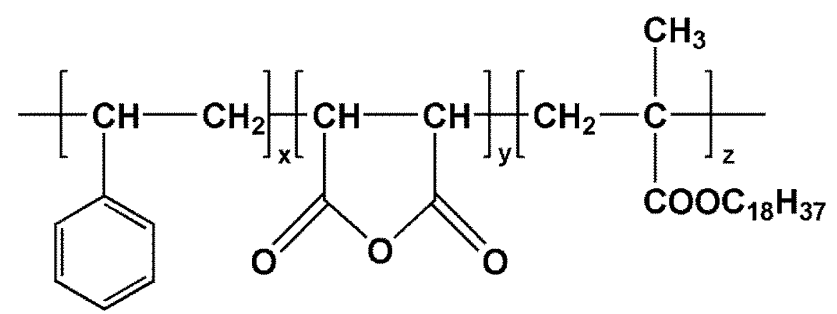

Fig. 18 Chemical structure of the terpolymer OMS

polyamine shows the highest inhibition efficiency of $66.2 \%$. After treated with PPC-2, the size of wax crystal in simulated crude was significantly reduced as shown in Fig. 16.

A new aminated copolymer (MAVA) functioning as a pour point depressant was synthesized by amination of terpolymer copolymerized with monomers octadecyl acrylate, maleic anhydride, and vinyl acetate (Fig. 17) (Fang et al. 2012; Zhang et al. 2009). After treated with the mixture of MAVA and EVA (mass ratio $=1: 3$ ) at the dosage of $400 \mathrm{ppm}$, the pour point of Shengli crude was dropped by $11{ }^{\circ} \mathrm{C}$. It was also found that the presence of asphaltene, resin, and pour point depressant plays a positive role in flowabiliy enhancement through formation of nucleators of the wax crystals.

Another terpolymer (Fig. 18) was synthesized by Shang et al. (2013) using octadecyl methacrylate(O), maleic anhydride $(\mathrm{M})$ and styrene(S) as monomers of polymerization. This reaction was initiated by benzoyl peroxide (BPO). This polymer can depress the wax deposition rate of the Xinjiang oilfield crude by $50 \%$. Moreover, the pour point and viscosity were also reduced after the crude treated with it.

Zhang et al. (2010, 2011, 2012) discussed some factors leading to serious wax deposition, such as wax carbon number, asphaltene and resin content, and gas-oil ratio, after which the performance of a polymeric wax crystal modifier consisted of polar and non-polar groups combining with surfactant was evaluated using five crudes. The results show that this mixture exhibits good wax inhibition functionality. The inhibiting rate can reach up to $66 \%$.

\section{Conclusions}

The primary objective of this paper is to review the recent advances on polymeric compounds that have been used as wax crystal modifiers for flowability improvement and/or wax inhibition in the petroleum industry aiming to provide an up to date overview of this topic. Based on the discussion, the following conclusions can be made:

1. The performance of wax crystal modifiers is strongly dependant on the capacity of polymer to co-crystallize with wax; in other words, it is related not only to structure of polymers but also to the composition of wax. For example, EVA 30 which contains 30 $\mathrm{wt} \%$ of vinly acetate is the most efficient polymer than EVA 20, 40, and 80; meanwhile, this copolymer is more effective for the systems having high carbon number paraffins. The efficiency of MAC polymers as flow improvers increases with the length of side chains.

2. Wax crystal modifiers are usually used combining with solvents, through which the wax inhibition efficiency could be further improved.

3. Asphaltenes exhibit different effects on the performance of wax crystal modifiers depending on the measured properties, such as yield stress, pour point, and wax deposition.

4. Numerous polymeric wax crystal modifiers have been experimentally investigated. However, theoretical modelings are extremely necessary to correlate the molecular structure of polymers with the corresponding performance to predict the efficiency of wax inhibition. 
Open Access This article is distributed under the terms of the Creative Commons Attribution License which permits any use, distribution, and reproduction in any medium, provided the original author(s) and the source are credited.

\section{References}

Al-Sabagh AM, Noor El-Din MR, Morsi RE, Elsabee MZ (2009) Styrene-maleic anhydride copolymer esters as flow improvers of waxy crude oil. J Pet Sci Eng 65:139-146

Al-Sabagh AM, El-Hamouly SH, Khidr TT, El-Ghazawy RA, Higazy SA (2013) Preparation the esters of oleic acid-maleic anhydride copolymer and their evaluation as flow improvers for waxy crude oil. J Dispers Sci Technol 34:1585-1596

Al-Yaari M (2011) Paraffin wax deposition: mitigation \& removal techniques. In: SPE-55412 presented at SPE Saudi Arabia section Young Professionals Technical Symposium. Dhahran, Saudi Arabia, pp 14-16

Ashbaugh HS, Fetters LJ, Adamson DH, Prud'homme RK (2002) Flow improvement of waxy oils mediated by self-aggregating partially crystallizable diblock copolymers. J Rheol 46:763-776

Ashbaugh HS, Guo X, Schwahn D, Prud'homme RK, Richter D, Fetters LJ (2005) Interaction of paraffin wax gels with ethylene/ vinyl acetate co-polymers. Energy Fuels 19:138-144

Bacon MM, Romero-Zerón LB, Chong KK (2010) Determining wax type: paraffin or naphthene? SPE J 15:969-974

Bello O, Fasesan S, Teodoriu C, Reinicke K (2006) An evaluation of the performance of selected wax inhibitors on paraffin deposition of Nigerian crude oils. Pet Sci Technol 24:195-206

Brar AS, Kumar R (2002) Influence of ethylene-co-vinyl acetate copolymers on the flow properties of wax synthetic systems. J Appl Polym Sci 85:1337-1348

Chen G, Tang Y, Zhang J (2011) Synthesis and application of polyaminoamide as new paraffin inhibitor from vegetable oil. Chem Cent J 5:82-84

Del Carmen García M (2000) Crude oil wax crystallization. The effect of heavy n-paraffins and flocculated asphaltenes. Energy Fuels 14:1043-1048

Didukh AG, Koizhaiganova RB, Bimendina LA, Kudaibergenov SE (2004) Synthesis and characterization of novel hydrophobically modified polybetaines as pour point depressants. J Appl Polym Sci 92:1042-1048

Dobbs JB (1999) A unique method of paraffin control in production operations. In: SPE-55647 presented at SPE Rocky Mountain Regional Meeting. Gillette, Wyoming, pp 15-18

El-Ghazawy RA, Farag RK (2010) Synthesis and characterization of novel pour point depressants based on maleic anhydride-alkyl acrylates terpolymers. J Appl Polym Sci 115:72-78

Fang L, Zhang X, Ma J, Zhang B (2012) Investigation into a pour point depressant for shengli crude oil. Ind Eng Chem Res 51:11605-11612

Gentili DO, Khalil CN, Rocha NO, Lucas EF (2005) Evaluation of polymeric phosphoric ester-based additives as inhibitors of paraffin deposition. In: SPE-94821 presented at SPE Latin American and Caribbean Petroleum Engineering Conference. Rio de Janeiro, Brazil, pp 20-23

Guo X, Adamson DH, Tinsley J, Pethica BA, Huang JS, Prud'homme RK (2004a) Synthesis of poly(ethylene-butene) random copolymers with hydroxylic grafts and the effect of polar groups on deposition of wax and asphaltenes from crude oil. In: PETR-16 presented at the 228th ACS National Meeting. Philadelphia

Guo X, Pethica BA, Huang JS, Prud'homme RK (2004b) Crystallization of long-chain n-paraffins from solutions and melts as observed by differential scanning calorimetry. Macromolecules 37:5638-5645

Guo X, Pethica BA, Huang JS, Prud'homme RK, Adamson DH, Fetters LJ (2004c) Crystallization of mixed paraffin from model waxy oils and the influence of micro-crystalline poly(ethylenebutene) random copolymers. Energy Fuels 18:930-937

Guo X, Tinsley J, Prud'homme RK (2005) Strategy of flow improvement for waxy oils by comb polymers. In: PETR-8 presented at the 230th ACS National Meeting. Washington

Guo X, Pethica BA, Huang JS, Adamson DH, Prud'homme RK (2006) Effect of cooling rate on crystallization of model waxy oils with microcrystalline poly(ethylene butene). Energy Fuels 20:250-256

Halim N, Ali S, Nadeem M, Abdul Hamid P, Mohd Tan I (2011) Synthesis of wax inhibitor and assessment of squeeze technique application for Malaysian waxy crude. In: SPE-142288 presented at SPE Asia Pacific Oil and Gas Conference and Exhibition. Jakarta, Indonesia, pp 20-22

Jafari Ansaroudi HR, Vafaie-Sefti M, Masoudi S, Jafari Behbahani T, Jafari H (2013) Study of the morphology of wax crystals in the presence of ethylene-co-vinyl acetate copolymer. Pet Sci Technol 31:643-651

Jennings DW, Breitigam J (2010) Paraffin inhibitor formulations for different application environments: From heated injection in the desert to extreme cold arctic temperatures. Energy Fuels 24:2337-2349

Jennings DW, Newberry ME (2008) Paraffin inhibitor applications in deepwater offshore developments. In: IPTC-12127 presented at International Petroleum Technology Conference. Kuala Lumpur, Malaysia, pp 3-5

Jiang QZ, Yue G, Song ZZ, Ke M, Zhao MF (2006) Relation between structure of ethene-vinylacetate copolymers and their pour point depression. J Southwest Pet Inst 28:71-74

Kudaibergenov SE, Didukh AG, Ibraeva ZE, Bimendina LA, Rullens F, Devillers M, Laschewsky A (2005) A regular, hydrophobically modified polyampholyte as novel pour point depressant. J Appl Polym Sci 98:2101-2108

Lashkarbolooki M, Esmaeilzadeh F, Mowla D (2011) Mitigation of wax deposition by wax-crystal modifier for Kermanshah crude oil. J Dispers Sci Technol 32:975-985

Leube W, Monkenbusch M, Schneiders D, Richter D, Adamson D, Fetters L, Dounis P, Lovegrove R (2000) Wax-crystal modification for fuel oils by self-aggregating partially crystallizable hydrocarbon block copolymers. Energy Fuels 14:419-430

Li L, Guo X, Adamson DH, Pethica BA, Huang JS, Prudhomme RK (2011) Flow improvement of waxy oils by modulating longchain paraffin crystallization with comb polymers: An observation by X-ray diffraction. Ind Eng Chem Res 50:316-321

Li L, Xu J, Tinsley J, Adamson DH, Pethica BA, Huang JS, Prud'homme RK, Guo X (2012) Improvement of oil flowability by assembly of comb-type copolymers with paraffin and asphaltene. AIChE J 58:2254-2261

Lindeman OE, Allenson SJ (2005) Theoretical modeling of tertiary structure of paraffin inhibitors. In: SPE-93090 presented at SPE International Symposium on Oilfield Chemistry. The Woodlands, Texas, pp 2-4

Machado ALC, Lucas EF, González G (2001) Poly(ethylene-co-vinyl acetate) (EVA) as wax inhibitor of a Brazilian crude oil: oil viscosity, pour point and phase behavior of organic solutions. J Pet Sci Eng 32:159-165

Marie E, Chevalier Y, Eydoux F, Germanaud L, Flores P (2005) Control of n-alkanes crystallization by ethylene-vinyl acetate copolymers. J Colloid Interface Sci 290:406-418

Monkenbusch M, Schneiders D, Richter D, Willner L, Leube W, Fetters LJ, Huang JS, Lin M (2000) Aggregation behaviour of 
PE-PEP copolymers and the winterization of diesel fuel. Phys B 276-278:941-943

Paso KG, Fogler HS (2004) Bulk stabilization in wax deposition systems. Energy Fuels 18:1005-1013

Pedersen KS, Rønningsen HP (2003) Influence of wax inhibitors on wax appearance temperature, pour point, and viscosity of waxy crude oils. Energy Fuels 17:321-328

Petinelli JC (1979) Effect of vinyl ethylene acetate copolymers on the nucleation and growth kinetics of n-paraffins in a hydrocarbon medium. Rev Inst Fr Petr 34:791-811

Qian JW, Zhou GH, Yang WY, Xu YL (2002) Studies on pour point depression of EVA polymers in solvent mixtures containing wax. J Appl Polym Sci 83:815-821

Radulescu A, Schwahn D, Stellbrink J, Kentzinger E, Heiderich M, Richter D, Fetters LJ (2006) Wax crystallization from solution in hierarchical morphology templated by random poly(ethylene-cobutene) self-assemblies. Macromolecules 39:6142-6151

Radulescu A, Schwahn D, Stellbrink J, Monkenbusch M, Fetters LJ, Richter D (2011) Microstructure and morphology of selfassembling multiblock poly(ethylene-1-butene)-n copolymers in solution studied by wide-Q small-angle neutron scattering and microscopy. J Polym Sci Part B Polym Phys 49:144-158

Raduuescu A, Schwahn D, Monkenbusch M, Fetters LJ, Richter D (2004) Structural study of the influence of partially crystalline poly(ethylene butene) random copolymers on paraffin crystallization in dilute solutions. J Polym Sci Part B Polym Phys 42:3113-3132

Schwahn D, Richter D, Lin M, Fetters LJ (2002a) Cocrystallization of a poly(ethylene-butene) random copolymer with $\mathrm{C} 24$ in n-decane. Macromolecules 35:3762-3768

Schwahn D, Richter D, Wright PJ, Symon C, Fetters LJ, Lin M (2002b) Self-assembling behavior in decane solution of potential wax crystal nucleators based on poly(co-olefins). Macromolecules 35:861-870

Shang HY, Ying XH, Huang CF, Duan BH, Fan G, Liu PC, Tian F, Liu CG (2013) Paraffin inhibitor development and performance evaluation in Xinjiang Oilfield. J Univ Petro China 37:167-172

Soni HP, Bharambe DP, Nagar A, Kiran B (2005) Synthesis of chemical additives and their effect on Akholjuni crude oil (Gujarat, India). Indian J Chem Technol 12:55-61

Soni HP, Kiranbala Bharambe DP (2008) Performance-based designing of wax crystal growth inhibitors. Energy Fuels 22:3930-3938

Soni HP, Kiran B, Agrawal KS, Nagar A, Bharambe DP (2010) Designing maleic anhydride- $\alpha$-olifin copolymeric combs as wax crystal growth nucleators. Fuel Process Technol 91:997-1004

Taraneh JB, Rahmatollah G, Hassan A, Alireza D (2008) Effect of wax inhibitors on pour point and rheological properties of Iranian waxy crude oil. Fuel Process Technol 89:973-977

Tinsley JF, Prud'homme RK, Guo X, Adamson DH, Callahan S, Amin D, Shao S, Kriegel RM, Saini R (2007a) Novel laboratory cell for fundamental studies of the effect of polymer additives on wax deposition from model crude oils. Energy Fuels 21:1301-1308

Tinsley JF, Prud'homme RK, Guo X, Adamson DH, Susan S, Amin D, Callahan S, Dettman HD, Kriegel R, Saini R (2007b) Effects of polymers on the structure and deposition behavior of waxy oils. In: SPE-106204 presented at International Symposium on Oilfield Chemistry. Houston, Texas, pp 28

Tinsley JF, Jahnke JP, Adamson DH, Guo X, Amin D, Kriegel R, Saini R, Dettman HD, Prud'home RK (2009) Waxy gels with asphaltenes 2: use of wax control polymers. Energy Fuels 23:2065-2074

Towler BF, Chejara AK, Mokhatab S (2007) Experimental investigations of ultrasonic waves effects on wax deposition during crudeoil production. In: SPE-109505 presented at SPE Annual Technical Conference and Exhibition. Anaheim, California, pp 11-14

Venkatesan R, Sampath V, Washington LA (2012) Study of wax inhibition in different geometries. In: OTC-23624 presented at Offshore Technology Conference. Houston, Texas, pp 30

Vieira LC, Buchuid MB, Lucas EF (2012) Effect of pressure on the performance of poly(ethylene-vinyl acetate) as wax deposition inhibitors by calorimetric method. J Appl Polym Sci 126:143-149

Wang KS, Wu CH, Creek JL, Shuler PJ, Tang Y (2003) Evaluation of effects of selected wax inhibitors on paraffin deposition. Pet Sci Technol 21:369-379

Wu C, Zhang JL, Li W, Wu N (2005) Molecular dynamics simulation guiding the improvement of EVA-type pour point depressant. Fuel 84:2039-2047

Xu J, Zhang X, Sun J, Li L, Guo X (2009) How comb-type poly(maleic acid alkylamide-co- $\alpha$-olefin) assemble in waxy oils and improve flowing ability. Asia Pac J Chem Eng 4:551-556

Yang F, Li CX, Lin MZ (2009) Depressive effects evaluation of ethylene-vinyl acetate copolymer on waxy crude oils. J Univ Pet China 33:108-113

Zhang J, Wu C, Li W, Wang Y, Cao H (2004) DFT and MM calculation: the performance mechanism of pour point depressants study. Fuel 83:315-326

Zhang J, Zhang M, Wan J, Li W (2008) Theoretical study of the prohibited mechanism for ethylene/vinyl acetate co-polymers to the wax crystal growth. J Phys Chem B 112:36-43

Zhang FX, Fang L, Nie ZG, Zhang XD (2009) Preparation and mechanism of a pour point depressant for high pour point crude oil. Acta Petrolei Sinica 25:801-806

Zhang F, Fang J, Zhu F, Lin H, Feng X (2010) Characteristics of PKKR crude oil of Kazakhstan and study on HS paraffin inhibitor. Acta Petrolei Sinica 26:712-717

Zhang F, Ouyang J, Hong L, Feng X, Zhang H (2011) Inhibition of deposits of high-molecular weight paraffins in oil wells. Chem Technol Fuels Oils 47:53-57

Zhang F, Ouyang J, Wang D, Feng X (2012) Mechanism of highcarbon paraffin deposition and preventing methods. Adv Mat Res 396-398:1102-1105

Zhang F, Ouyang J, Feng X, Zhang H, Xu L (2014) Paraffin deposition mechanism and paraffin inhibition technology for highcarbon paraffin crude oil from the Kazakhstan PK oilfield. Pet Sci Technol 32:488-496 